\title{
Bladder Preservation with Concurrent Radiotherapy and Gemcitabine following Maximal Transurethral Resection for Muscle Invasive Bladder Cancer: Single Institutional Experience
}

\author{
Mutahir A. Tunio*, Mushabbab Al Asiri, Mohsin Fareed, Shoaib Ahmed, Yasser Bayoumi and Abdullah Amro
}

Department of Radiation Oncology, Comprehensive Cancer Center, King Fahad Medical City, Riyadh, PO 59046, Saudi Arabia

\begin{abstract}
Objectives: For bladder preservation, cisplatinum is widely used radiosensitizer with concurrent chemoradiation (CRT). We aimed to evaluate the safety profile and potential benefit of gemcitabine as a radiosenistizer in bladder preservation.

Patients and methods: During July 2006 to January 2007, consecutive 32 patients with T2-T4N0M0 bladder cancer underwent transurethral resection of bladder tumor (TURBT) followed by concurrent chemoradiation with weekly gemcitabine $100 \mathrm{mg} / \mathrm{m}^{2}$. Conformal radiotherapy was given with a shrinking field technique. Complete response was defined as no visible tumor on cystoscopy and biopsy.

Results: Of total, 26 patients received a median of 7 (3-8) cycles of gemcitabine and median cumulative radiation dose of 65 Gy. Grade 3 hematologic toxicities seen were; neutropenia (3.8\%) and thrombocytopenia $(7.7 \%)$. Grade 3 non-hematologic toxicities were; diarrhea $(19.2 \%)$, nausea/vomiting $(7.7 \%)$ and cystitis $(15.4 \%)$. Complete response was achieved in 18 patients $(69.2 \%$ [95\% Cl: $60-89 \%])$. At median follow up of 36 months, four patients had local recurrences (two superficial and two muscle invasive). The overall intact bladder and overall survival rates were $75.1 \%$ and $56.3 \%$, respectively.
\end{abstract}

Conclusion: CRT with weekly gemcitabine was found feasible and highly active in the treatment of muscle invasive bladder cancer, as the 3 year intact bladder survival rates were promising.

Keywords: Muscle invasive bladder cancer; Bladder preservation; Gemcitabine; Radiosensitizer; Intact bladder and overall survival

\section{Introduction}

In Saudi Arabia, bladder cancer is the 10th and the 20th most common cancer in males and females and the smoking is main cause of bladder cancer according to the King Faisal Specialist Hospital and Research Center (KFSH \& RC) Cancer Registry [1], 'which is much lower as compared to the most of developing countries; where bladder cancer is most common urologic malignancy [2]. According to the treatment, bladder cancer is categorized into, superficial (noninvasive), muscle invasive and metastatic disease [3]. Muscle invasive bladder cancer is traditionally treated with radical cystectomy with long term survival rates around 50\% [4]. Even the new surgical techniques including construction of neobladder with continent urinary diversion cannot substitute for the original bladder [5]. An alternative option is the bladder preservation incorporating maximal transurethral resection of bladder tumor (TURBT) and concurrent chemoradiation (CCRT) and it has demonstrated similar overall survival around $50 \%$ to radical cystectomy [6,7]. Cisplatinum is commonly used as a radiosensitizer; however, this agent has significant toxicity, limiting its utility. In Radiation Therapy Oncology Group (RTOG) 85-12, for example, only 30 of 42 assessable patients were able to complete the entire therapy per protocol [8].

Gemcitabine, a nucleoside analog has shown significant activity as a radiosensitizer in various preclinical and clinical studies $[9,10]$. Additionally, cisplatinum is not a choice as radiosensitizer in patients with compromised renal functions.

On the basis of these data, this study was undertaken prospectively to determine the complete response rates, safety profile with radiation, disease free and overall survival rates with intact functional bladder in conjunction with a weekly gemcitabine concurrent with radiation as a bladder preservation option.

\section{Patients and Methods}

After taking written consent, consecutive patients with muscle invasive bladder cancer were enrolled between July 2006 and January 2007 and were followed up until January 2010.

\section{Eligibility}

After protocol approval by institutional review board, patients were enrolled. At time of enrollment, eligible patients were required to have; histopathological proven muscle invasive transitional cell carcinoma of bladder; European Cooperative Oncology Group (ECOG) performance status 0-2; American Joint Committee on Cancer (AJCC) stage T2b-T4aN0M0; baseline full capacity functioning bladder; maximum transurethral resection of bladder tumor (TURBT) at time of CCRT; normal hematology with hemoglobin $\geq 10 \mathrm{gm} / \mathrm{dl}$, white blood cells $(\mathrm{WBC}) \geq 4000 / \mathrm{mm}^{3}$, platelets $\geq 100,000 / \mathrm{mm}^{3}$ and

*Corresponding author: Mutahir A. Tunio, MBBS, FCPS (Radiation Oncology) Assistant Professor, Department of Radiation Oncology, Comprehensive Cancer Center, King Fahad Medical City, Riyadh, PO 59046, Saudi Arabia, Tel: +996 12889999; E-mail: drmutahirtonio@hotmail.com

Received January 19, 2012; Accepted February 16, 2012; Published February 20, 2012

Citation: Tunio MA, Asiri MA, Fareed M, Ahmed S, Bayoumi Y, et al. (2012) Bladder Preservation with Concurrent Radiotherapy and Gemcitabine following Maximal Transurethral Resection for Muscle Invasive Bladder Cancer: Single Institutional Experience. J Nucl Med Radiat Ther 3:121. doi:10.4172/2155-9619.1000121

Copyright: ( 2012 Tunio MA, et al. This is an open-access article distributed under the terms of the Creative Commons Attribution License, which permits unrestricted use, distribution, and reproduction in any medium, provided the original author and source are credited. 
Citation: Tunio MA, Asiri MA, Fareed M, Ahmed S, Bayoumi Y, et al. (2012) Bladder Preservation with Concurrent Radiotherapy and Gemcitabine following Maximal Transurethral Resection for Muscle Invasive Bladder Cancer: Single Institutional Experience. J Nucl Med Radiat Ther 3:121. doi:10.4172/2155-9619.1000121

Page 2 of 5

normal renal functions (serum creatinine $\leq 2.0 \mathrm{mg} / \mathrm{dl}$ or creatinine clearance $\geq 60 \mathrm{ml} / \mathrm{min}$ ) and normal electrolyte values.

Patients with concurrent Tis or superficial bladder cancer, any lymphadenopathy or distant metastasis, with poor performance status, prior chemotherapy, radiotherapy or prior history of malignancy were excluded. Hydronephrosis was not included as exclusion criteria. Attempts were made to correct renal functions by percutaneous nephrostomy $(\mathrm{PCN})$ or urinary diversion.

\section{Treatment protocol} TURBT.

All patients underwent CCRT within 6 weeks after maximal

Transurethral resection of bladder tumor (TURBT): After meeting with eligibility criteria, all patients underwent cystoscopic evaluation including examination under spinal anesthesia; Bi-manual examination was carried out before and after TURBT. Cystoscopy was performed by experienced urologist and maximal TURBT was defined as no visible tumor after resection. Visually maximal TURBT in one or more attempts. The small residuals after second sitting of TURBT were also eligible.

Radiation therapy: All patients were simulated on virtual simulator and three dimensional (3D) conformal planning was performed. Radiotherapy was given with shrinking field technique
(Figure 1), (1) initial phase included whole pelvis, covered by four fields anteroposterior (AP), posteroanterior (PA), two opposing lateral fields (right and left lateral) to encompass the entire bladder, prostate, and pelvic lymph nodes. The field borders were at the L5-S1 interspace cephaled, at laterally $1 \mathrm{~cm}$ beyond bony pelvis, and the inferior margin of obturator foramen caudally. The dose given was $45 \mathrm{~Gy}$ with fraction size 1.8 Gy in 25 fractions, five days/a week, (2) in boost phase; multiple radiation fields were used to cover the gross tumor volume only with 1 $\mathrm{cm}$ margin. The boost dose to gross tumor volume was given $20 \mathrm{~Gy}$ with fraction size $2 \mathrm{~Gy}$ in ten fractions to complete cumulative $65 \mathrm{~Gy}$. The maximum doses to the posterior rectal wall and to the femoral heads were kept 55 Gy and 45 Gy, respectively. All radiation was delivered by 6 to $15 \mathrm{MV}$ photons from multileaf collimator (MLC) based linear accelerator.

Chemotherapy: Gemcitabine $100 \mathrm{mg} / \mathrm{m}^{2}$ intravenously was given weekly, 30 minutes prior to radiation for six weeks. During CRT, dose was modified on a weekly basis. If the WBC count was $<2,000 / \mathrm{mm}^{3}$ or platelet count was $<50,000 / \mathrm{mm}^{3}$, all chemotherapy for that week was omitted. If the WBC count was $<1,000 / \mathrm{mm}^{3}$ or platelet count was $<25,000 / \mathrm{mm}^{3}$, CCRT was withheld until WBC count and platelet counts recovered to $\geq 1,000 / \mathrm{mm}^{3}$ and $25,000 / \mathrm{mm}^{3}$, respectively. For grade 3 or more non-hematological toxicity gemcitabine was withheld for that week and radiation was continued if score changed to grade 2 .
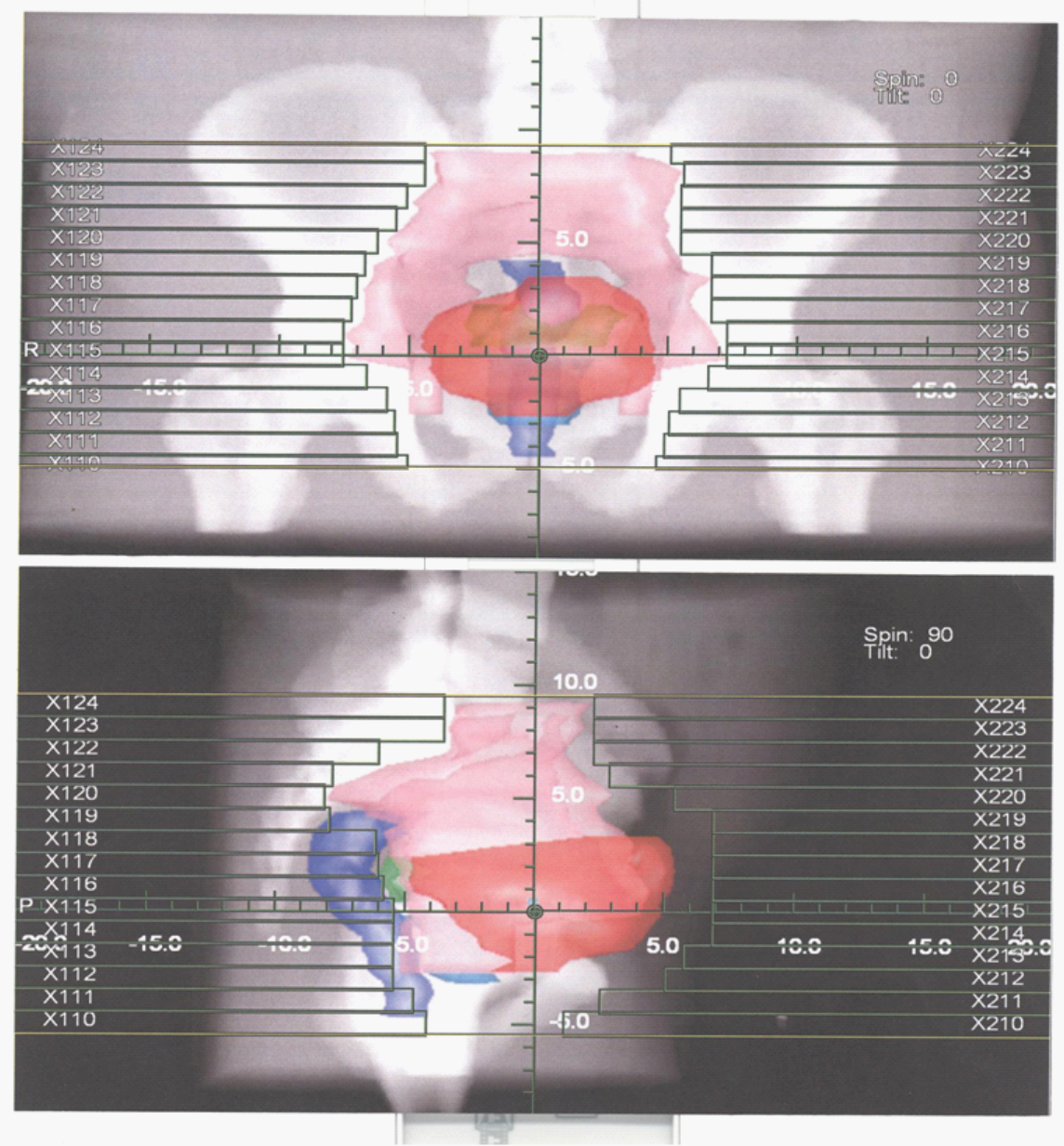

Figure 1: Four field Box Technique irradiating pelvic lymph nodes, along with gross tumor volume 
Citation: Tunio MA, Asiri MA, Fareed M, Ahmed S, Bayoumi Y, et al. (2012) Bladder Preservation with Concurrent Radiotherapy and Gemcitabine following Maximal Transurethral Resection for Muscle Invasive Bladder Cancer: Single Institutional Experience. J Nucl Med Radiat Ther 3:121. doi:10.4172/2155-9619.1000121

Page 3 of 5

\section{Toxicity and assessment evaluation}

During CCRT, patients were evaluated every week for weight, performance status, hematology/chemistry and other related symptoms. The National Cancer Institute Common Toxicity Criteria (NCI-CTC) version 2.0, were used to score acute radiation and chemotherapy toxicity ( $\leq 90$ days from start of radiation therapy). The Radiation Therapy Oncology Group (RTOG) Late Radiation Morbidity Scoring Criteria were used to score radiation toxicity persisting beyond 90 days from the completion of radiotherapy.

Follow-up: Check cystoscopy was performed after the completion of treatment and biopsy was taken only in selected cases with suspected residual disease. Patients were considered to have achieved a complete response (CR) if no evidence of visible tumor on cystoscopy / biopsy and urine cytology showed any malignancy. Patients with CR or only superficial tumor ( $\mathrm{Ta}$, Tis, or $\mathrm{T} 1)$ at a new site were followed as bladder preservation. Patients with any residual tumor at the original tumor site or muscle-invasive tumor (T2 or greater) at a new site underwent salvage cystectomy. During the follow up period, patients underwent check cystoscopy 6 weeks after completion of concurrent chemoradiation, and then every 3 months for first year and every 6 months for following years. During follow up, superficial recurrences were treated with complete TURBT and intravesical therapy (intravesical bacilli Calmette-Guerin BCG; Connaught strain, $81 \mathrm{mg} / 50 \mathrm{ml}$ ) over 6 weeks induction course and then each week for 3 weeks. Recurrent muscle invasive tumors were treated with salvage cystectomies. For distant metastasis, bone scan, CT chest, abdomen and pelvis were repeated every 6 months after completion of treatment.

\section{Statistical analysis}

The primary endpoints were the effectiveness of the regimen in terms of safety profile, and response rates and the secondary points were local recurrence and distant metastasis. The times to last follow up evaluation, appearance of local and distant relapse and death were calculated from date of starting treatment. Disease free survival (DFS) was defined as the duration between the entry date and the date of documented disease reappearance, death from cancer and/or last follow-up (censored). Overall survival (OS) was defined as the duration between the entry date and the date of patient death or last follow-up (censored). Probabilities of local and distant control, disease free and the overall survival were determined with the Kaplan-Meier method. The comparisons for various endpoints were performed using log rank test and Cox regression analysis. Statistical analyses were performed using the computer program SPSS version 16.0.

\section{Results}

\section{Patient characteristics}

A total 22 males and 10 females with mean age 60.06 years (range 36-75) with muscle invasive bladder cancer were treated (Table 1). 15 patients $(46.9 \%)$ were with radiological stage T3N0M0. Nine patients (28.1\%) had hydronephrosis at time of enrollment, for which all of these patients underwent percutaneous nephrostomy (PCN). Complete TURBT was performed in 22 patients $(68.8 \%)$ in one or more attempts. All patients had ECOG performance status 0-1.

\section{Initial response and treatment related toxicity}

For 32 patients, acute non-hematological grade 3 side effects of concurrent chemoradiation were nausea \& vomiting $15.6 \%$ (5 patients), diarrhea $18.7 \%$ (6 patients) and cystitis in $18.7 \%$ (6 patients). The G4 side effects were only cystitis seen in $3.0 \%$ cases. The acute hematological grade 3 toxicities were neutropenia 3.1\% (1 patient) and thrombocytopenia $6.2 \%$ (2 patients) (Figure 2 ). The weekly gemcitabine was omitted for one course in three patients; however, no dose reduction was seen during course of radiation.

Out of 32 patients, 26 patients underwent first check cystoscopy and biopsy at 3 months following CRT. Remaining six patients were lost to follow up. The complete response (CR) on first check cystoscopy/ tumor site biopsy at 3 months following concurrent chemoradiation, was seen in 18 patients $(69.2 \%, 95 \%$ confidence interval $\{\mathrm{CI}\} 60-89)$. Of 8 patients, who did not achieve $\mathrm{CR}$, all underwent salvage cystectomies.

Late side effects at one year after treatment were seen in only two patients $(7.7 \%)$ were consistent with mild irritative bladder symptoms. No delayed gastrointestinal or hematological toxicity were observed.

\section{Local recurrences, distant metastasis, survival and disease free survival}

At the median follow-up period of 36 months (24-38 months), local recurrences were seen in 4 patients (15.4\%) out of 18 initial complete responders. Two (7.7\%) had superficial bladder cancers (pT1, G2) and were treated with complete TURBT followed by intravesical bacillus Calmette-Guerin (BCG). Two (7.7\%) had muscle invasive cancer, for which salvage cystectomy was performed.

Toxicity profile ( all grades): Concurrent gemcitabine and radiation (32 patients)

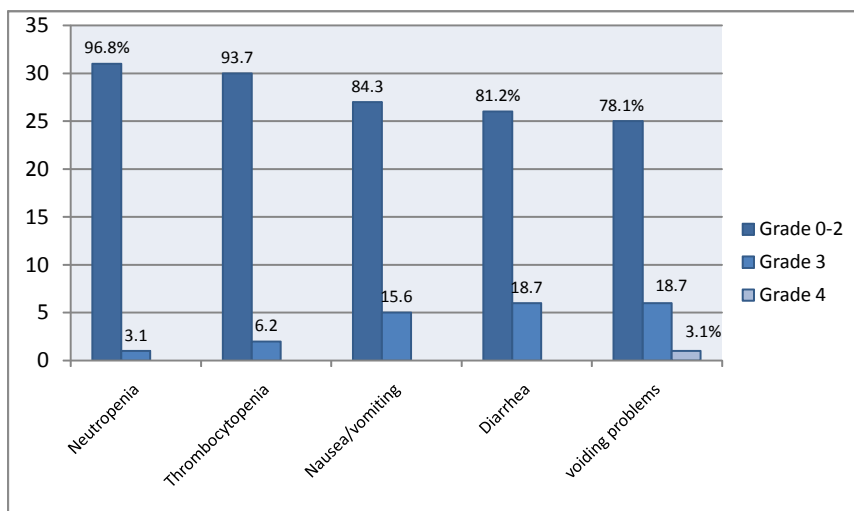

Figure 2: Acute Toxicity profile of 32 patients received concurrent chemoradiation with gemcitabine.

\begin{tabular}{|c|c|}
\hline Variable & Number $(\%)$ \\
\hline Age & 60.06 years (range $36-75$ ) \\
\hline \multicolumn{2}{|l|}{ Gender } \\
\hline Male & $22(68.7)$ \\
\hline Female & $10(31.3)$ \\
\hline \multicolumn{2}{|l|}{ Clinical Stage } \\
\hline T2NOMO & $10(31.2)$ \\
\hline T3N0MO & 15 (46.9) \\
\hline T4NOMO & $7(21.9)$ \\
\hline \multicolumn{2}{|l|}{ Hydronephrosis } \\
\hline No & $23(71.9)$ \\
\hline Yes & $9(28.1)$ \\
\hline \multicolumn{2}{|c|}{ Visible complete TURBT performed } \\
\hline Yes & $22(68.7)$ \\
\hline No & $10(31.3)$ \\
\hline \multicolumn{2}{|l|}{ ECOG } \\
\hline $0-2$ & $32(100)$ \\
\hline $3-4$ & 0 \\
\hline
\end{tabular}

Table 1: Patient characteristics. 
Citation: Tunio MA, Asiri MA, Fareed M, Ahmed S, Bayoumi Y, et al. (2012) Bladder Preservation with Concurrent Radiotherapy and Gemcitabine following Maximal Transurethral Resection for Muscle Invasive Bladder Cancer: Single Institutional Experience. J Nucl Med Radiat Ther 3:121. doi:10.4172/2155-9619.1000121

Page 4 of 5

Bony metastases were seen in three patients (11.5\%); and were treated with salvage chemotherapy, palliative radiotherapy for pain relief and bisphosphonates.

At the time of analysis 14 patients initial 18 complete responders (77.78\%) continued to retain their original bladder and were free of disease. Using the Kaplan-Meier method, over intact bladder rates $75.1 \%$ were at 3 years and 3 year survival was found to be $56.3 \%$ (Figure $3)$.

On Cox-regression analysis, significant differences in survival were found between the subgroups of hydronephrosis (presence vs. absence) (log-rank p 0.0001), primary Tumor stage (<T3 vs. more than T3) (logrank p 0.0001), initial complete response (yes vs. no) and incomplete TURBT (yes vs. no) (log-rank p 0.001).

\section{Discussion}

The current standard of care for muscle-invasive bladder cancer is radical cystectomy. Trimodality treatment, including maximal transurethral resection of the bladder tumor (TURBT) followed by concurrent chemoradiation has been shown to produce five year survival rates in the range of 50-60\%, comparable with those of cystectomy [11,12]. With this bladder preservation strategy, cystectomy has been reserved for patients with incomplete response or local invasive recurrence [8]. The majority of these trials have used cisplatinum as a radiosensitizer. However, reported grade 3 and 4 hematologic and non-hematologic toxicities were considerable in the neoadjuvant or non neoadjuvant resulting in poor compliance and outcome assessment [13].

In the present study, gemcitabine was given for its proven potent radiosensitizer properties. Gemcitabine was well tolerated in our study population. Six patients could not complete the treatment protocol owing to their socioeconomic reasons. We observed more non hematological side effects including nausea, vomiting (15.6\%) and diarrhea (18.7\%). The possible explanation could be that, we used initial large pelvic fields to irradiate pelvic lymph nodes. However, similarly designed study by Kent $\mathrm{E}$ et al. reported no grade 3 gastrointestinal toxicity by using bladder fields [14]. Further, we did not see any deranged liver function tests in our patient population. In our study, all patients were treated by 3D-CRT; however the acute side effects may further increase if conventional methods of radiation are used.

We used gemcitabine $100 \mathrm{mg} / \mathrm{m}^{2}$ weekly, different from other similar designed trials $[15,16]$ to increase the compliance which was (100\%) in our study population.

Our study resulted in 3 year overall survival rates of $56.3 \%$ and with intact bladder disease free disease free survival rates of $75.1 \%$. These
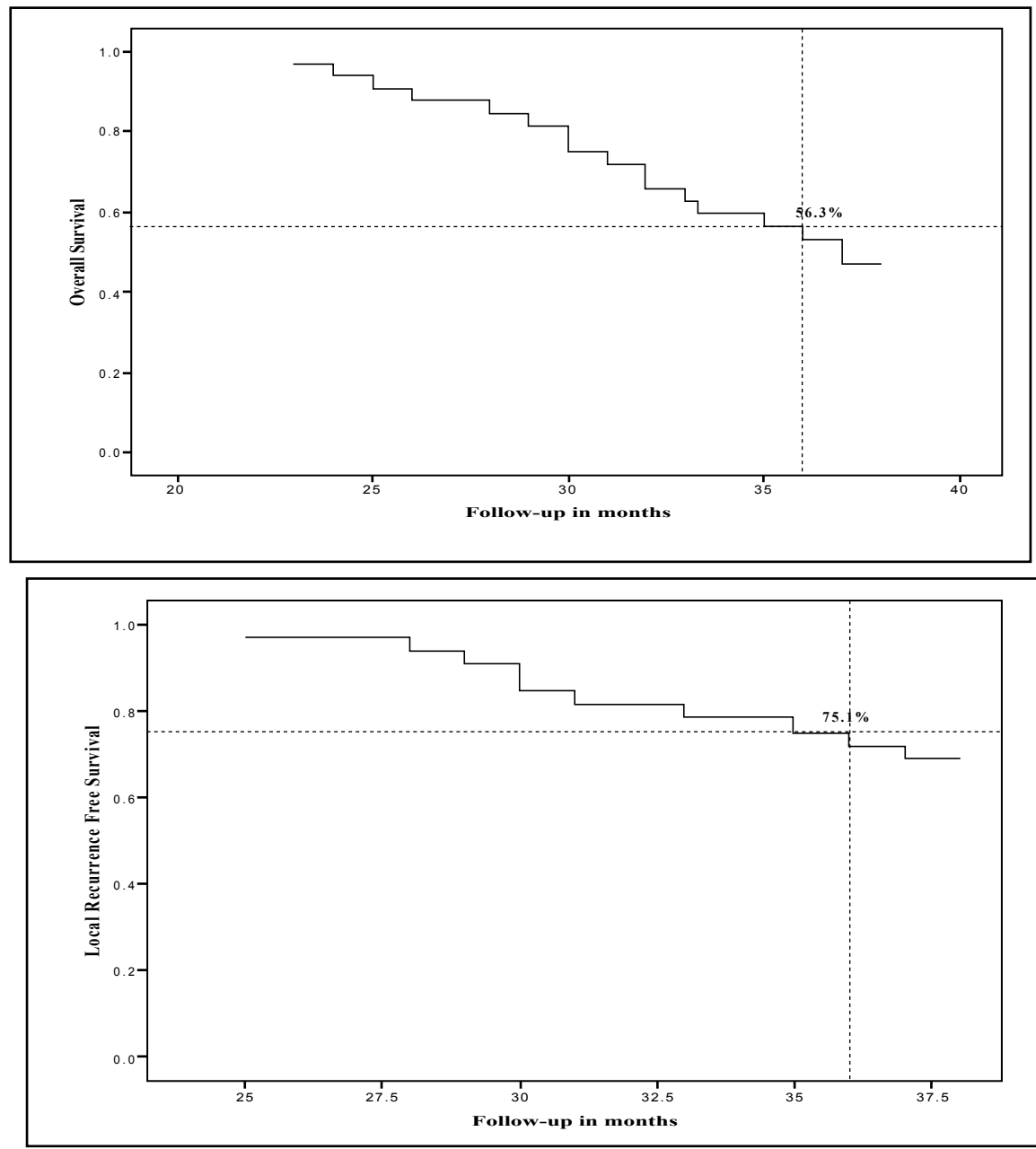

Figure 3: 3 year local recurrence free and overall survival rates. 
Citation: Tunio MA, Asiri MA, Fareed M, Ahmed S, Bayoumi Y, et al. (2012) Bladder Preservation with Concurrent Radiotherapy and Gemcitabine following Maximal Transurethral Resection for Muscle Invasive Bladder Cancer: Single Institutional Experience. J Nucl Med Radiat Ther 3:121. doi:10.4172/2155-9619.1000121

Page 5 of 5

\begin{tabular}{|c|c|c|c|c|}
\hline $\begin{array}{c}\text { Study } \\
\text { (reference) }\end{array}$ & Patients & Regimen & CR & $\begin{array}{l}\text { Toxicity } \\
\text { Grade } 3\end{array}$ \\
\hline Kent E et al [14] & 24 & RT $60 \mathrm{~Gy} \div 30$ fractions + gemcitabine MTD $10-30 \mathrm{mg} / \mathrm{m}^{2}$ twice weekly & $91 \%$ & $\begin{array}{l}\text { Hepatic: } 3 \text { patient } \\
\text { Diarrhea: } 1 \text { patient } \\
\text { Neutropenia: } 1 \text { patient }\end{array}$ \\
\hline Caffo O et al. [17] & 16 & $\begin{array}{l}\text { RT } 54 \mathrm{~Gy} \div 30 \text { fractions }+ \\
\text { gemcitabine } \\
\text { MTD } 400 \mathrm{mg} / \mathrm{m}^{2} \text { weekly+ cisplatin } 100 \mathrm{mg} / \mathrm{m}^{2} \text { q } 3 w \mathrm{ks}\end{array}$ & $100 \%$ & NA \\
\hline Sangar VK et al. [18] & 8 & $\begin{array}{l}\text { RT } 52.5 \mathrm{~Gy} \div 20 \text { fractions +gemcitabine } \\
\text { MTD } 150 \mathrm{mg} / \mathrm{m}^{2} \text { once weekly }\end{array}$ & $88 \%$ & $\begin{array}{l}\text { Cystitis: } 1 \text { patient } \\
\text { Diarrhea: } 1 \text { patient }\end{array}$ \\
\hline Present study & 32 & $\begin{array}{l}\text { RT } 65 \mathrm{~Gy} \div 35 \text { fractions +gemcitabine } \\
100 \mathrm{mg} / \mathrm{m}^{2} \text { weekly }\end{array}$ & $69.2 \%$ & $\begin{array}{l}\text { Diarrhea: } 6 \text { patients } \\
\text { Nausea and vomiting: } 5 \text { patients } \\
\text { Neutropenia: } 1 \text { patient } \\
\text { Thrombocytopenia: } 2 \text { patient } \\
\text { Cystitis: } 1 \text { patient }\end{array}$ \\
\hline
\end{tabular}

$\mathrm{NA}=$ not available

Table 2: comparison of present study with similar other published studies.

results are comparable to other similarly designed studies (Table 2). The presence of the hydronephrosis and advanced T stage, absence of post treatment complete response and incomplete TURBT are generally considered poor prognostic factors affecting the survival in patients undergo either radical cystectomy or bladder preservation $[19,20]$. Our study cohort was mainly with $\mathrm{T}$ stage $>\mathrm{T} 3$ and hydronephrosis; for these patients continent diversion is difficult after radical cystectomy. Our study did not evaluate the DNA ploidy, tumor grade and HER 2 over-expression which are considered additional poor prognostic factors $[21,22]$.

\section{Conclusion}

Although the follow up period was shorter to evaluate the prognostic factors influencing the survival and bladder preservation, bladder preservation with concurrent gemcitabine and radiation therapy is adequate option for patients with no hydronephrosis, lower T stage ( $<$ T3) and with maximum complete TURBT.

\section{References}

1. Mokhtar AA, El-Sebaie MM, Elkum N (2004) Predictors of outcome after radical cystectomy for bladder cancer in Saudi Patients; Single Institution Experience. J Egypt Natl Canc Inst 16: 137-144.

2. Tunio M, Rafi M, Maqbool A, Haque A (2009) Virtual simulation and treatment verification-merits and demerits: Experience at Sindh Institute of Urology and Transplantation (SIUT). J Radiother Pract 8: 131-136.

3. Cheng L, Montironi R, Davidson DD, Lopez-Beltran A (2009) Staging and reporting of urothelial carcinoma of the urinary bladder. Mod Pathol 22: S70-95.

4. Joung JY, Han KS, Kim TS, Seo HK, Chung J, et al. (2008) Single institutional experience of bladder-preserving trimodality treatment for muscle-invasive bladder cancer. J Korean Med Sci 23: 598-603.

5. Shipley WU, Kaufman DS, Zehr E, Heney NM, Lane SC, et al. (2002) Selective bladder preservation by combined modality protocol treatment: long term outcomes of 190 patients with invasive bladder cancer. Urology 60: 62-68.

6. Solsona E, Climent MA, Iborra I, Collado A, Rubio J, et al. (2009) Bladder preservation in selected patients with muscle-invasive bladder cancer by complete transurethral resection of the bladder plus systemic chemotherapy: long-term follow-up of a phase 2 nonrandomized comparative trial with radical cystectomy. Eur Urol 55: 911-919.

7. Kaufman DS, Winter KA, Shipley WU, Heney NM, Wallace HJ 3rd, et al. (2009) Phase I-II RTOG study (99-06) of patients with muscle-invasive bladder cancer undergoing transurethral surgery, paclitaxel, cisplatin, and twice-daily radiotherapy followed by selective bladder preservation or radical cystectomy and adjuvant chemotherapy. Urology 73: 833-837.

8. Tester W, Porter A, Asbell S, Coughlin C, Heaney J, et al. (1993) combined modality therapy with possible organ preservation for invasive bladder carcinoma: Results of RTOG protocol 85-12. Int J Radiat Oncol Biol Phys 25: 783-790.

9. Latz D, Fleckenstein K, Eble M, Blatter J, Wannenmacher M, et al. (1998) Radiosensitizing potential of gemcitabine (2',2'-difluoro-2'-deoxycytidine) within the cell cycle in vitro. Int J Radiat Oncol Biol Phys 41: 875-882.

10. Lawrence TS, Chang EY, Hahn TM, Hertel LW, Shewach DS (1996) Radiosensitization of pancreatic cancer cells by 2',2'-difluoro-2'-deoxycytidine. Int J Radiat Oncol Biol Phys 34: 867-872.

11. Michaelson MD, Shipley WU, Heney NM, Zietman AL, Kaufman DS (2004) Selective bladder preservation for muscle invasive transitional cell carcinoma of the urinary bladder. $\mathrm{Br} \mathrm{J}$ cancer $90: 578-581$.

12. Lin CC, Hsu CH, Cheng JC, Huang CY, Tsai YC, et al. (2009) Induction cisplatin and fluorouracil-based chemotherapy followed by concurrent chemoradiation for muscle-invasive bladder cancer. Int J Radiat Oncol Biol Phys 75: 442-448.

13. Efstathiou JA, Bae K, Shipley WU, Kaufman DS, Hagan MP, et al. (2009) Late pelvic toxicity after bladder-sparing therapy in patients with invasive bladder cancer: RTOG 89-03, 95-06, 97-06, 99-06. J Clin Oncol 27: 4055-4061.

14. Kent E, Sandler H, Montie J, Lee C, Herman J, et al. (2004) Combined-modality therapy with gemcitabine and radiotherapy as a bladder preservation strategy: results of a phase I trial. J Clin Oncol 22: 2540-2545.

15. Oh KS, Soto DE, Smith DC, Montie JE, Lee CT, et al. (2009) Combined-modality therapy with gemcitabine and radiation therapy as a bladder preservation strategy: long-term results of a phase I trial. Int J Radiat Oncol Biol Phys 74: 511-517.

16. Herman JM, Smith DC, Montie J, Hayman JA, Sullivan MA, et al. (2004) Prospective quality-of-life assessment in patients receiving concurrent gemcitabine and radiotherapy as a bladder preservation strategy. Urology 64 $69-73$

17. Caffo O, Fellin G, Graffer U, Valduga F, Bolner A, et al. (2003) Phase I study of gemcitabine and radiotherapy plus cisplatin after transurethral resection as conservative treatment for infiltrating bladder cancer. Int J Radiat Oncol Bio Phys 57: 1310-1316.

18. Sangar VK, McBain CA, Lyons J, Ramani VA, Logue JP, et al. (2005) Phase I study of conformal radiotherapy with concurrent gemcitabine in locally advanced bladder cancer. Int J Radiat Oncol Biol Phys 61: 420-425.

19. Scrimger RA, Murtha AD, Parliament MB, Venner PM, Hanson J, et al. (2001) Muscle-invasive transitional cell carcinoma of the urinary bladder: a populationbased study of patterns of care and prognostic factors. Int J Radiat Oncol Biol Phys 51: 23-30.

20. Adiyat KT, Katkoori D, Soloway CT, De los Santos R, Manoharan M, et al (2010) "Complete transurethral resection of bladder tumor": are the guidelines being followed? Urology 75: 365-367.

21. Deliveliotis C, Georgoulakis J, Skolarikos A, Trakas N, Varkarakis J, et al. (2005) DNA ploidy as a prognostic factor in muscle invasive transitional cell carcinoma of the bladder. Urol Res 33: 39-43.

22. Niu HT, Xu T, Zhang YB, Pang DQ, Zhang ZL, et al. (2008) Outcomes for a large series of radical cystectomies for bladder cancer. Eur J Surg Oncol 34: 911-915. 